Article

\title{
An Evaluation of Irrigation Water Use Efficiency in Crop Production Using a Data Envelopment Analysis Approach: A Case of Louisiana, USA
}

\author{
Tej K. Gautam ${ }^{1}$, Krishna P. Paudel ${ }^{2, *}$ and Kurt M. Guidry ${ }^{3}$ \\ 1 Rice Research \& Extension Center, University of Arkansas System Division of Agriculture, \\ Stuttgart, AR 72160, USA; tkgautam@uark.edu \\ 2 Department of Agricultural Economics and Agribusiness, Louisiana State University (LSU) and LSU \\ Agricultural Center, Baton Rouge, LA 70803, USA \\ 3 H. Rouse Caffey Rice Research Station, LSU Agricultural Center, Baton Rouge, LA 70526, USA; \\ kmguidry@agcenter.lsu.edu \\ * Correspondence: kpaudel@agcenter.lsu.edu
}

Received: 9 September 2020; Accepted: 10 November 2020; Published: 15 November 2020

\begin{abstract}
The primary objective of this study is to estimate and evaluate the technical efficiency of irrigation water use in soybean (Glycine max L.) production in Louisiana, USA. We conducted a farm-level survey to assess information regarding irrigation cost, the volume of water application, and crop yield per acre during the crop year 2016. We use smoothed heterogeneous bootstrapping procedures in conventional data envelopment analysis (DEA) and supplement it with a nonradial measure of efficiency known as the Russell measure. The irrigation efficiency scores obtained from both an input- and an output-based DEA approach indicate that producers are over-applying irrigation water by approximately 37 percent. The results provide evidence that an improvement in water management practices can optimize irrigation efficiency, leading to higher profits for the farmers by lowering the other input prices in the production process. The findings should provide a benchmarking tool to formulate an appropriate irrigation policy that enhances water conservation in crop production in regions with similar environmental conditions and soil characteristics.
\end{abstract}

Keywords: irrigation efficiency; data envelopment analysis; groundwater; Louisiana; soybeans; survey

\section{Introduction}

Irrigation water use efficiency improvement and crop productivity are major concerns in the agricultural sector [1]. Water use efficiency is directly associated with farm profitability, soil health, water quality, water conservation, and sustainable use [2,3]. According to the United States Department of Agriculture (USDA) report, around $70 \%$ of the total cropland was irrigated using groundwater and surface water sources in 2017 in Louisiana (United States Department of Agriculture (USDA), Crop Acreage Data (2017). Available at: http://www.fsa.usda.gov/news-room/efoia/electronic-readingroom/frequently-requested-information/crop-acreage-data/index) It is well recognized that irrigation water application efficiency is relatively lower in a furrow irrigation system than in center pivot and drip irrigation systems [4,5]. However, a furrow/flood irrigation system has been the most commonly practiced irrigation method in Louisiana. The adoption of surge valves, flow meters, and soil moisture sensors in irrigation practices can significantly reduce water use, while still providing the required amount of water for crops. However, in a recent survey conducted by the authors of this study in Louisiana, more than $50 \%$ of the respondents reported that they use furrow irrigation, and the majority of them have not yet adopted surge valves, flow meters, and soil moisture sensors. 
Sargent [6] mentioned that Louisiana farmers withdrew approximately $180 \mathrm{Mgal} /$ day of groundwater and $57 \mathrm{Mgal} /$ day of surface water for crops other than rice (Oryza sativa L.) in 2009. $\left(1\right.$ million gallon $\left.(\mathrm{Mgal})=3785.4 \mathrm{~m}^{3}\right)$ Water withdrawals increased in 37 of the 64 parishes (Parish is an equivalent administrative division in Louisiana as county in other U.S. states.) in Louisiana by $58 \%$ from 2005 to 2010, during which time groundwater withdrawals for general irrigation increased by $16 \%$ and surface-water withdrawals increased by $22 \%$. Additionally, water use for general irrigation occurred primarily in northeastern Louisiana, where $85 \%$ (160 Mgal/day) of the groundwater was withdrawn from the Mississippi River Alluvial Aquifer [6]. This scenario indicates some sort of irrigation water use inefficiency that needs to be identified by an appropriate estimation method. Surprisingly, groundwater for general irrigation withdrawals in Louisiana has increased by $780 \%$ since 1960, as Sargent indicates [6]. If that trend continues, groundwater overexploitation increases the risk of water table decline, which leads to water quality deterioration and increases the pumping cost. It is commonly known that an extra inch/acre of irrigation water use imposes an additional cost to farmers that reduces the net farm profit. In response to the potential risk associated with water quality and quantity, water conservation effort is one of the tools for sustainable water resources use. For this, appropriate water management is an essential step towards that goal. It is an agreed-upon fact that under-irrigation and over-irrigation both have drawbacks in terms of nutrient leaching, susceptibility to disease, water loss, and loss in yield. Under-irrigation generally results in low production and quality, whereas over-irrigation may result in environmental pollution because of possible nutrient leaching, additional water pumping cost, unproductive use of energy for pumping water, and disease possibility. In response to the need to manage water resources, efficiency analysis would provide valuable insights to enable producers to optimize productivity, minimize farm operation cost leading to optimal profit, minimize water loss, and minimize environmental degradation. Irrigation efficiency information would provide producers with the means to re-evaluate their irrigation scheduling to achieve higher water application productivity.

Many studies have evaluated irrigation scheduling in terms of irrigation technology, efficiency, and profitability under water supply constraints. Peterson and Ding [7] evaluate the effect of irrigation efficiency on irrigation water use in the High Plains (Ogallala) Aquifer. They indicate that optimal irrigation does not respond monotonically to efficiency changes, although intermediate and high-efficiency systems result in less water use than an inefficient flood system. Paudel et al. [8] developed a dynamic model to optimize irrigation water allocation during water deficit periods for three major crops grown in the humid southeastern United States. However, it did not address the irrigation efficiency concerns. Most of the studies in irrigation efficiency are agronomic or engineering based. The present study uses a nonparametric approach to estimate irrigation efficiency and provides economic interpretations.

The primary aim of this study is to estimate the technical efficiency (TE) of irrigation water use in soybean (Glycine max L.) production using a nonparametric method and suggest appropriate policy tools to minimize irrigation inefficiency. TE measures a decisionmaker's capability to produce the maximum possible outputs from a given set of inputs or produce a given output level using the minimum possible amount of inputs. This information would allow producers to manage existing production practices efficiently. In an evaluation of sustainable farming, production efficiency and irrigation water use productivity need to be incorporated. Farmers may seek to maximize production and profit per unit of water, known as financial sustainability. In contrast, the environmentally sustainable system seeks to minimize irrigation water use in the production process [9]. These two contrasting approaches between financial and social sustainability to efficiency regarding agricultural productivity and resource conservation require a management approach that simultaneously takes into consideration sustainability, agricultural productivity, and net profit [10]. To achieve such sustainable production, evaluating irrigation efficiency would provide a benchmarking tool to access water efficiency at the farm level and provide valuable information to improve farm productivity. 
The remainder of this paper is organized in the following way. Section 2 provides a relevant literature review concerning irrigation and production efficiency analysis using a data envelopment approach. Section 3 presents the model specification and estimation process. Section 4 provides data descriptions. Section 5 discusses the estimated results, and Section 6 addresses the policy implications and limitations of this study.

\section{Literature Review}

The data envelopment analysis (DEA) is a nonparametric method of measuring efficiency. The nonparametric method does not impose restrictions on the functional form, and it is more flexible than the parametric method. It assumes that there is no random error, measurement error, or an outlier in the data. Because of its flexibility, many researchers have been using the DEA method to analyze efficiency in many sectors. Pereira and Marques [11] provide a comprehensive review of the empirical literature on methodologies applied to measure irrigation efficiency and, out of 32 studies, find $87.5 \%$ estimated irrigation efficiency using the DEA method. They conclude that, in general, farms are considerably inefficient with respect to water use. Additionally, they note that some factors, such as agricultural training, larger farm size, installing localized irrigation, having access to better credit opportunities, extension services, right crop choice, education, and being an owner-operated farm, can contribute to an improved efficiency level [11]. Some of the major studies relevant to irrigation water efficiency analysis using the DEA method are summarized in the succeeding paragraphs.

In the case of limited irrigation water availability, if a specific irrigation union controls the irrigation water supply, irrigation water productivity is influenced by the water union's managerial capability. For instance, Sayin and Yilmaz [12] estimate the relative efficiency scores of irrigation unions in Turkey using an input-oriented DEA method and find pure technical efficiency (TE) and scale efficiency (Scale efficiency (SE) of a farm is determined by the ratio of TE under constant returns to scale (CRS) and TE under variable returns to scale (VRS) expressed as $S E=\frac{T E_{C R S}}{T E_{V R S}}$, where $S E \leq 1$. It means that the $\mathrm{SE}$ of the farm is attributed to the presence of increasing returns to scale or decreasing returns to scale. If $\mathrm{SE}=1$, we should understand that the farm is operating at the maximum level) to be 0.81 and 0.95 , respectively. However, the efficiency scores obtained from the conventional DEA method may not be precise because it provides a radial measure of efficiency, ignoring the slacks in the constraints. For a better understanding of efficiency scores, the issue of slacks needs to be corrected. Russell measures of TE can take into account this issue. In this line of study, Lansink and Ondersteijn [13] evaluate productivity growth in Dutch greenhouse firms using Russell measures of TE of energy use and notice that the critical factor driving the process of productivity growth is technical progress. In another context, Dhungana et al. [14] estimate the economic inefficiency of Nepalese rice farms with 76 samples using a two-stage DEA method and find the average relative economic, allocative (The allocative efficiency (AE) measures the ability of a technically efficient farm to use inputs in the proportion that tends to reduce production costs), technical, pure technical, and scale inefficiencies to be 34, 13, 24, 18, and 7, respectively. In another context, Watto and Mugera [15] estimate the comparative irrigation efficiency for those who need to purchase irrigation water and for those who can pump water from their tube well in sugarcane production in Pakistan using a conventional DEA method. The estimated results indicate that the mean TE score is 0.96 for a tube-well owner and 0.94 for water buyers. However, the efficiency scores seem to be inflated as the authors have implemented the radial measure of TE, which cannot estimate efficiency scores correctly.

Irrigation efficiency analysis at the regional level provides some insight into improving water productivity by formulating and employing better water management policy in a broader context. In this line, Wang et al. [16] examine agricultural water use efficiency in the Heihe River Basin, China, with a three-stage DEA method using time series data from 2004 to 2013. The estimated results indicate that the TE and scale efficiency decreased in the study area. Simultaneously, the pure TE increased, indicating that the scale adjustment is essential to the agricultural production area. The findings and recommendations are purely based on regional level analysis linked to a small-scale situation. In fact, 
the farm level efficiency analysis can provide more accurate insights toward improving irrigation water use and production efficiency on a microscale farm basis.

Some of the studies evaluate allocative and irrigation water use efficiency at the province level, comprising economic subdivisions, social subsystems, and cities, using time series data. For example, Ren et al. [17] analyze water resource use efficiency in Gansu Province, China using the DEA method and find that the water use efficiency of the socioeconomic system in that province has consistently increased from 2004 to 2013.

Godanakis et al. [18] analyze horticulture farm productivity and water use efficiency in England using a DEA method. They use data from 66 horticultural farms and reveal that farms in the sample can reduce water requirements by $35 \%$ on average while achieving the same output level. Furthermore, they indicate that $47 \%$ of farms operate under an increasing return to scale, which implies that farms need to develop economies of scale to achieve an input minimization situation. In another context, Ntantos and Karpouzos [19] conduct a study concerning irrigation performance evaluation in Greece using a DEA method and show that the average TE of the irrigation systems in the study area is around $70 \%$.

Ali and Klein [20] estimate the water use efficiency and productivity of irrigation districts in Southern Alberta, Canada, using both the input-oriented and the output-oriented DEA method utilizing the time-series data from the period of 2008-2012. The estimated results from the input-oriented model indicate that the average TE of the irrigation districts is $84.3 \%$, and the output-oriented results show that irrigation districts can expand their total irrigated areas by $58.3 \%$ at the current level of input use. However, this study suffers from some limitations, such as a lack of net amount of water use data.

DEA is widely used to evaluate efficiency in firms other than agricultural sectors, such as financial sectors, tourism, educational institutions, production, and many more. For example, Liu et al. [21] use the DEA-Tobit method to estimate 53 Chinese coastal cities' tourism eco-efficiency. Likewise, Goyal et al. [22] estimate overall TE, pure TE, and scale efficiency of 101 textile forms across India using the DEA method. They find that the technical inefficiency of Indian textile firms is about $16.44 \%$.

The studies mentioned above indicate that the degree of irrigation water use efficiency and TE varies by region, water availability, types of irrigation and production technology used, land characteristics, operational management, and producers' characteristics. Most of the studies have employed the DEA approach to estimate efficiency. While reviewing the relevant literature on irrigation and production efficiency analyses, we note a very limited number of studies that have focused on U.S. irrigation efficiency from an economic perspective. Except for Watkins et al. [23-25], most U.S. focused studies are either from an agronomic or engineering perspective. In the case of Louisiana, this is the first study that uses primary farm-level survey data and estimates irrigation efficiency. The findings of this study would have significant policy implications for water conservation, production efficiency, and farm profit.

\section{Method}

DEA Method

DEA is a nonparametric approach to measuring the efficiency of decision-making units (DMUs) using a linear programming model. In this study, DMUs represent producers making irrigation decisions on farms. Charnes et al. [26] is a pioneer who came up with the DEA method to estimate efficiency under the constant returns to scale (CRS) assumption. Later on, Banker et al. [27] introduce an efficiency analysis method for variable returns to scale (VRS) that enables researchers to decompose efficiency into TE and scale efficiency. The basic concept of efficiency can be explained using Figure 1, which shows a single input-output production system for five DMUs under CRS, VRS, and nonincreasing returns to scale (NIRS). The frontier lines under these technologies are shown in Figure 1. The frontiers define the optimal possible output for a given input. As a result, the $Y$ value 
of a DMU cannot exceed the output conditions, and hence the point cannot be found above the VRS frontier. Here, $X$ and $Y$ are the unitless input and output along the $X$-axis and $Y$-axis, respectively.

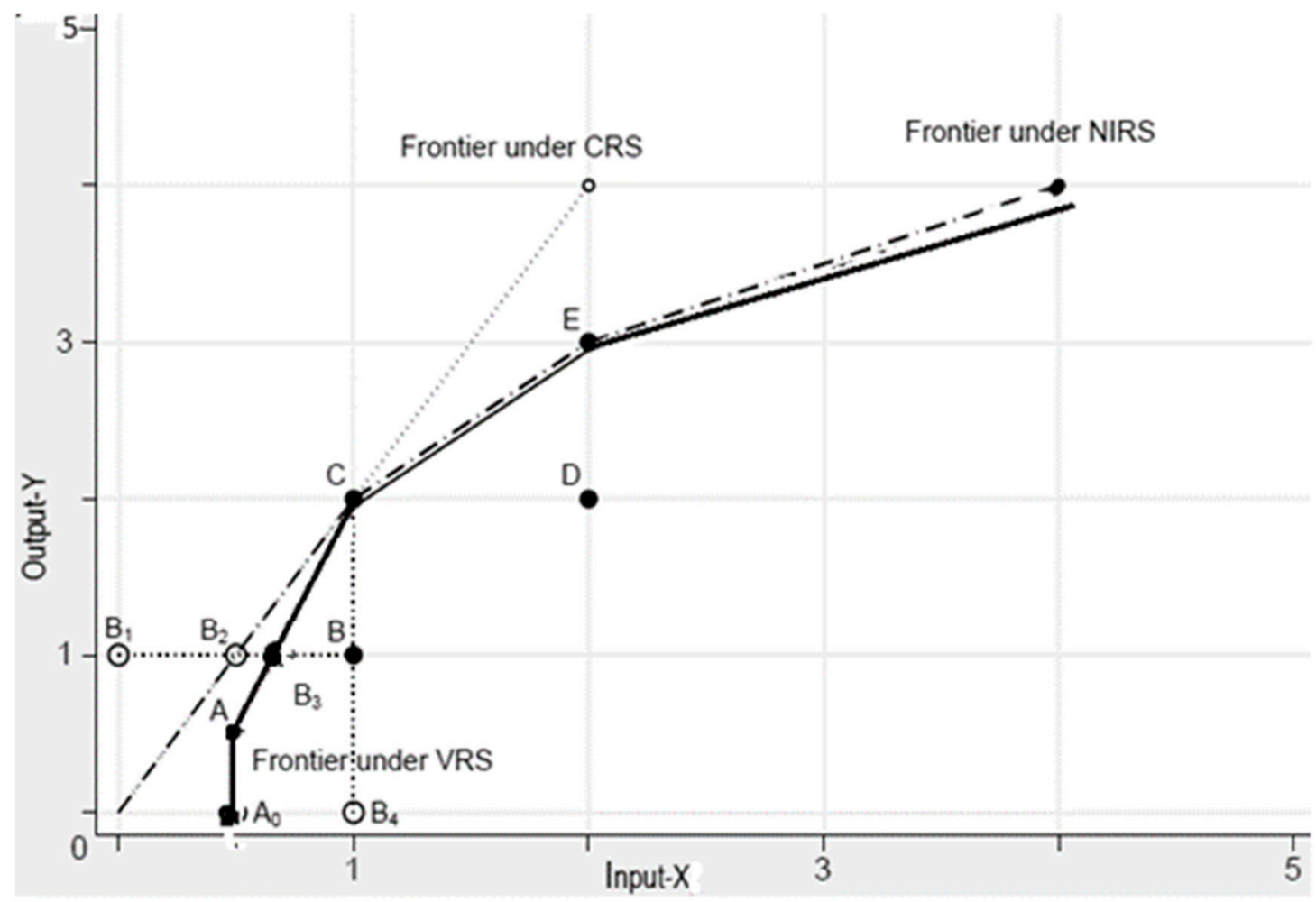

Figure 1. Concepts of efficiency and returns to scale (figure source: modified from Ji and Lee [28], Coelli et al. [29], and Cooper et al. [30]). CRS, constant returns to scale; VRS, variable returns to scale; NIRS, nonincreasing returns to scale.

In Figure 1, as explained by Ji and Lee [28], only point $C$ is efficient under CRS production technology; points $\mathrm{A}, \mathrm{C}$, and $\mathrm{E}$ are efficient under VRS; and point $\mathrm{E}$ is efficient under decreasing returns to scale (DRS). Point $B$ is inefficient and is operating under increasing returns to scale (IRS). Input-oriented efficiency relative to the VRS frontier can be defined as $\phi_{B, i n p u t, V R S}=\frac{\overline{B_{1} B_{3}}}{\overline{B_{1} B}}$; relative to the CRS frontier, it is defined as $\phi=\frac{\overline{B_{1} B_{2}}}{\overline{B_{1} B}}$, where $1-\phi$ indicates the proportion of input that can be reduced while achieving the same output level. The terms with overbar indicate the Euclidean distance between the two points. They can be calculated using an appropriate formula depending on the dimension of the space as defined by the number of inputs and outputs. Additionally, CRS technical inefficiency can be decomposed into scale efficiency and pure TE. For example, $\overline{B_{3} B}$ and $\overline{B_{2} B}$ contribute to the TE of $\mathrm{B}$ under VRS and CRS technology, respectively, and $\overline{B_{2} B_{3}}$ contributes to scale efficiency. Indeed, efficiency is the measure of relative distance to the frontier.

Figure 2 demonstrates the basic concept of efficiency, slacks, and references in the production process. The term "slack" is an input level that exceeds a level sufficient for producing optimal output. Slacks relate to the further increases in output or reduction in input depending on the type of DEA model under consideration (input-based or output-based model) that could be gained beyond that inferred by the radial projection. Figure 2 represents the production frontier for two input cases and one output case. Technically inefficient farms operate at a point interior of the frontier because the ratio of input to the output at a point within the concave area of the frontier curve is greater than that on the frontier curve. Optimal efficiency produces the most output with the minimum input, and thus the frontier curve along the points $\mathrm{A}$ to $\mathrm{F}$ defines where $X 2 / Y$ and $X 1 / Y$ are minimized. A DMU operating at that point is called efficient in terms of radial, technical, and weak efficiency. However, the efficient 
farms operate along the technology frontier line, in which the efficiency score is one and slacks value would be zero, as defined by Cooper et al. [30]. Here, A to F are the hypothetical points considered on the frontier line to explain the concept of relative efficiency and slacks in a simple manner.

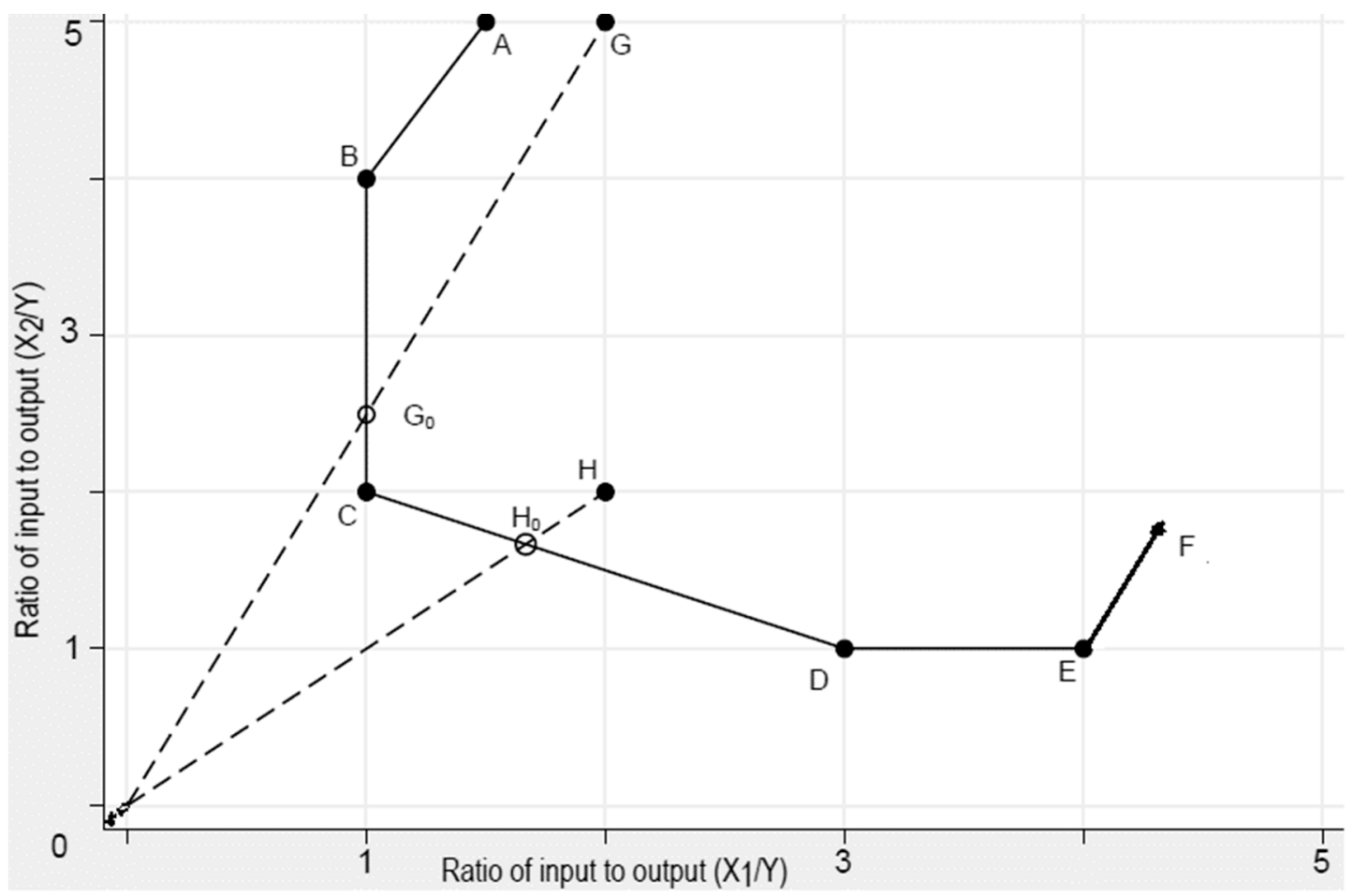

Figure 2. CRS input-oriented data envelopment analysis (DEA) example (figure source: modified from Ji and Lee [28], Coelli et al. [29], and Cooper et al. [30]).

The TE of $\mathrm{G}$ and $\mathrm{H}$ can be defined by the expressions $\frac{\overline{O G_{0}}}{\overline{O G}}$ and $\frac{\overline{O H_{0}}}{\overline{O H}}$, respectively. Although point $G_{0}$ is Farrell efficient (the efficient DMU in the frontier as measured by radial DEA model) ("Farrell efficient" indicates the efficient unit in the frontier as measured by classical DEA model. In simple words, Farrell [29] defined two measures of technical efficiency (input-based and output-based) assuming CRS. An efficient DMU under this condition is referred to as Farrell efficient. The input-based measure considers scaling inputs of inefficient units projecting the point radially to the frontier without changing output level, and the output-based measure considers scaling outputs of inefficient units projecting the point radially to the frontier without altering the inputs level.), input $X_{2}$ can be reduced further while achieving the same level of output. In this case, $C G_{0}$ is the input slacks for farm $G$. The first stage DEA model calculates the efficiency residually by disregarding the slacks. The Russell measure takes into account these possible slacks.

The aforementioned diagrammatic explanation of DEA analysis gives a conceptual idea in a two-dimensional framework representing single input and output variables. However, diagrammatic illustration of DEA for multiple inputs and outputs is complicated. Thus, we extend the two-dimensional model to a multidimensional form using mathematical expressions capable of accommodating multiple inputs and outputs.

Cooper et al. [30] define input-oriented CRS efficiency by applying the piecewise linear frontier to the input requirement set. This makes it easier to evaluate the efficiency relative to the frontier [28]. We can express a linear programming model for multiple inputs and outputs in the following mathematical form:

$$
\max _{\eta, \mu} \theta=\mu y_{j}
$$

Subject to $\eta x_{j}=1,-\eta X+\mu Y \leq 0, \eta \geq 0, \mu \geq 0$, and $\mu_{j}$ is free in sign. 
Here, $x_{j}$ and $y_{j}$ are input and output vectors, $X$ and $Y$ are input and output matrices, $\mu$ and $\eta$ are output and input multipliers, and a set of decisionmaking units (DMUs) is represented by $D M U_{j}, j=1,2, \ldots, n$. The input-oriented DEA model aims to minimize inputs relative to the same output level, subject to the constraints such that no DMUs can operate beyond the production possibility set and the constraint relating to nonnegative weights [28]. In most DEA studies, a dual form is commonly used because it is comparatively easier in estimation and provides almost the same result as that obtained using Equation (1).

The input-oriented measure of TE of the $j$ th DMU is calculated by solving the following linear programming model, which is the dual form of Equation (1):

$$
\min _{\phi, v} \phi
$$

Subject to $\phi x_{j}-X v \geq 0, Y v \geq y_{j}$, and $v \geq 0$.

Here, $v$ is a semi-positive vector in the kth space of a real number system and $\phi$ is a real variable that measures the TE. For simplicity, Equation (2) can be expressed in the following form.

$$
\begin{gathered}
\min _{\phi} \phi \\
\min _{v, s^{+}, s^{-}} \sum-s^{+}-s^{-}
\end{gathered}
$$

Subject to $\phi x_{j}-X v-s^{-}=0, Y v+s^{+}=y_{j}$, and $v \geq 0$.

The symbols $s^{+}$and $s^{-}$are semipositive vectors in the kth space of a real number system. Single-stage DEA estimation uses Equation (3) and the two-stage estimation uses Equation (3) followed by Equation (4). Here, $\phi$ is the TE score that lies in the interval $0 \leq \phi \leq 1$. If its value is 1 , the associated DMU is on the frontier, and $1-\phi$ indicates the percent of input use that can be reduced while achieving the same output level. In the case of returns to scale selection, Coelli et al. [31] suggested that the CRS model is suitable only if the DMU is operating at an optimal level. Because of various constraints, such as financial, operational, managerial, and input use, most of the DMUs may not operate at an optimal level. In this case, the variable returns to scale (VRS) technology would be appropriate. To convert into VRS production technology, a convexity constraint needs to be added as suggested by Banker et al. [27]. Now, the TE is decomposed into pure TE (PTE) and scale efficiency (SE).

The efficiency estimation in the above case is based on a radial measure that ignores the possibility of slack that may occur in the constraints. A Russell measure is used to accommodate such slacks as proposed by Färe and Lovell [32]. The input-oriented nonradial measure for data set $\left(x_{j}, y_{j}\right)$ is defined by the following mathematical expression [33]:

$$
R M_{j}^{i n}\left(y_{j}, x_{j}, y, x \mid C R S\right)=\min \left\{\begin{array}{ll}
N^{-1} \sum_{n=1}^{N} v_{n}: \begin{array}{l}
\left(v_{1} x_{j 1} \ldots v_{N} y_{j N}\right) \in L(y) \\
v_{n} \geq 0, n=1 \ldots N
\end{array}
\end{array}\right\}
$$

In the mathematical expression, we can define $\mathrm{N}$ inputs as $x_{j}=x_{j 1}, x_{j 2} \ldots x_{j N}$ and $\mathrm{M}$ inputs as $y_{j}=y_{j 1}, y_{j 2} \ldots y_{j M}$. However, in our empirical work, we use six input variables and one output variable.

For the output-oriented nonradial measure, it can be defined as follows:

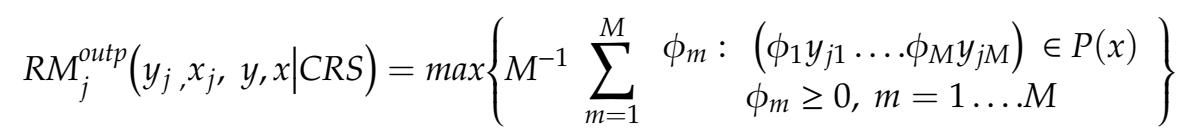

The input-oriented Russell measure for positive input can be obtained by solving the following linear programming problem (ibid): 


$$
R \hat{M}_{j}^{i n}\left(y_{j}, x_{j}, y, x \mid C R S\right)=N^{-1} \min _{\phi, \theta} \sum_{n=1}^{N} v_{n}
$$

$$
\text { Subject to } \sum_{j=1}^{J} \theta_{j} y_{j m} \geq y_{j m}, m=1,2 \ldots, M \sum_{j=1}^{J} \theta_{j} x_{j n} \leq x_{j n} v_{n}, n=1,2, \ldots, N \text {, and } \theta_{j} \geq 0
$$

If input $x_{j n}=0$, then the linear programming problem in Equation (7) is modified by setting up $v_{n}=1$. The Russell measurement process allows for a non-proportional reduction in each positive input, and this measurement collapses to the radial measure when $v_{n}=v, \forall n$, where $x_{j n}>0$. The Russell measure can reduce an input vector at least as far as the radial measure can have the result in the following range (ibid):

$$
0<R \hat{M}_{j}^{i n}\left(y_{j}, x_{j}, y, x \mid C R S\right) \leq F_{j}^{i n}\left(y_{j}, x_{j}, y, x \mid C R S\right) \leq 1
$$

In NRS and VRS production technology, an appropriate restriction on intensity vector $\theta$ is imposed, and then the Russell measure can be calculated. In a single input and output model, the Russell measure is equal to the radial measure. Similarly, the output-oriented Russell measure for positive output can be obtained by solving the following linear programming problem.

$$
\begin{gathered}
R \hat{M}_{j}^{\text {outp }}\left(y_{j}, x_{j}, y, x \mid C R S\right)=M^{-1} \max _{\phi, \theta} \sum_{m=1}^{M} \phi_{m} \\
\text { Subject to } \sum_{j=1}^{J} \theta_{j} y_{j m} \geq y_{j m} \phi_{m}, m=1,2 \ldots, M \sum_{j=1}^{J} \theta_{j} x_{j n} \leq x_{j n}, n=1,2, \ldots, N \text {, and } \theta_{j} \geq 0
\end{gathered}
$$

Here, $\mathrm{k}$ is used to express the number of production inputs. The Russell measure can reduce an output vector at least as far as the radial measure can have a result in the following range:

$$
1 \geq \hat{F}_{j}^{\text {outp }}\left(y_{j}, x_{j}, y, x \mid C R S\right) \geq R \hat{M}_{j}^{\text {outp }}\left(y_{j}, x_{j}, y, x \mid C R S\right)
$$

We use the stata command developed by Badunenko and Mozharovskyi [33] to calculate nonradial efficiency. It has bootstrap options to obtain statistical inferences, and it allows us to test hypotheses concerning technology dependency as well.

\section{Data Description}

This study uses primary farm-level data from Louisiana soybean producers for the crop year 2015-2016 collected by the authors of this study. We sent out survey questionnaires to 1680 Louisiana soybean producers. Out of the total questionnaires sent out, 451 envelopes were returned because of an address error or because some of the farmers retired. From the total sample of 1229, considering the sampling adjustment, 123 responses were obtained. The response rate of the survey was 10 percent. However, only 67 observations out of 123 responses have complete information that can be used for this study. We combined this dataset into 16 samples consisting of per acre water pumped, irrigation costs, and per acre soybean yield obtained from a detailed verification survey conducted in 2016. For this study, we treat crop yield as an output variable and per acre quantity of water applied during the crop year, irrigation costs such as energy cost, labor cost, and maintenance/repair cost as input variables. This means the study utilizes six inputs variables and one output variable in the efficiency estimation process. Summary statistics and variable definitions are displayed in Table 1. From Table 1, on average, per acre of water applied in soybean production during a crop year is 109,500 gallons. We received information about the volume of water pumped per hour, the number of irrigations made during a crop year, and the total number of hours of water pumped during each irrigation. 
Table 1. Descriptive statistics of variables used in efficiency analysis.

\begin{tabular}{llcc}
\hline Variable & Variable Description & Mean & Standard Deviation (SD) \\
\hline YIELD & Per acre soybean yield (bushel) & 58.26 & 9.20 \\
WATER & Water applied per acre (in 1000 gallons) & 109.50 & 128.64 \\
LABPOC & Labor and poly pipe cost per acre in dollar & 26.19 & 30.01 \\
REPCOS & Total repair and maintenance cost in dollar & 2807.29 & 4984.19 \\
ENGC & Per acre energy cost in dollar & 24.64 & 24.64 \\
ACRE & Acres of irrigated farm & 321.10 & 421.49 \\
WELLSIZE & Well size in inch & 9.48 & 2.83 \\
\hline
\end{tabular}

Based on this information, the average amount of water applied per acre is calculated by dividing the total water pumped by the irrigated acres of land. The average soybean yield per acre was 58 bushels ( 1 metric ton $=36.67$ bushels), and the average poly pipe and labor costs per acre were $\$ 25$. On average, producers spent 2807 dollars for repair and maintenance of their irrigation systems during a crop year (repair and maintenance cost represents the average total dollar amount spent during a crop year). Energy cost is the major cost for irrigation as water is almost free in Louisiana. On average, farmers spent $\$ 24$ per acre for pumping water, and the average number of soybean irrigated acres was 321. The average well diameter among farmers who responded to the survey was 9.5 inches. Regarding the concentration of soybean irrigated farms who responded to the survey, $10 \%$ of the irrigated farms were located in the north and northwest region, 39\% of the soybean farms were in the northeast region, $30 \%$ were in the central region, and the remaining $20 \%$ were in the south region based on our survey information. Soil characteristics, water holding capacity, and moisture level varied by region. We obtained a survey response from the farmers with farmland located in the northeastern, eastern, and central parts of Louisiana. The shaded regions with green color in Figure 3 represent the study area.

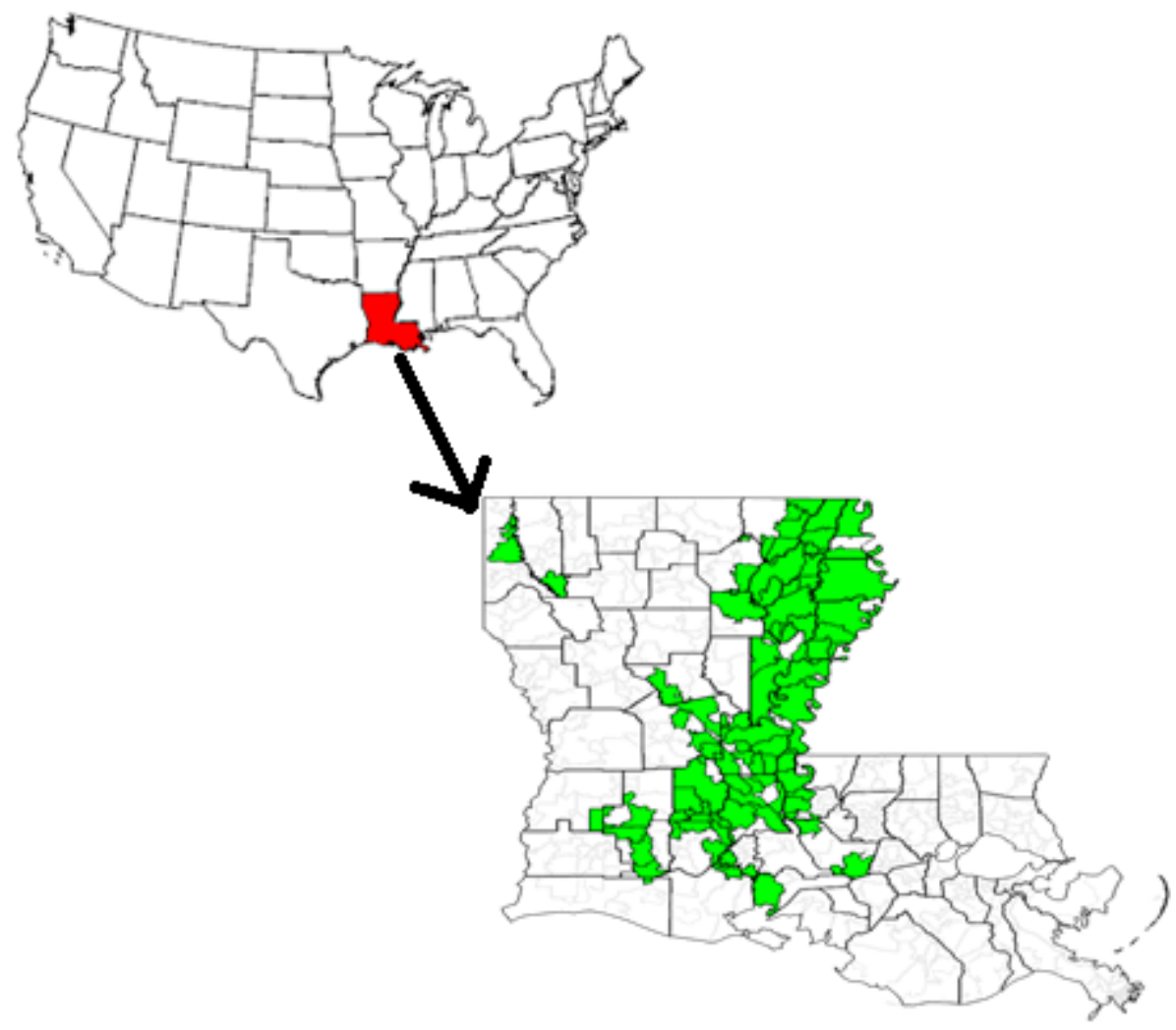

Figure 3. Map of the U.S. contiguous states with the State of Louisiana highlighted in red. The study area under consideration in Louisiana is shown in green. 


\section{Results and Discussion}

Table 2 displays both the radial (Farrell measure) and nonradial (Russell measure) scores of TE using the input-based and output-based measures. We estimate TE assuming VRS, CRS, and NIRS production technologies, but report the results of VRS and NIRS only in Table 2. For extended results, Table 3 displays the summary of estimated efficiency scores under all three production technologies.

Table 2. Radial and nonradial measure of technical efficiency (TE) using the data envelopment analysis (DEA) approach under VRS and NIRS assumption.

\begin{tabular}{ccccc}
\hline Method & \multicolumn{2}{c}{ Radial TE (Farrell Measure) } & \multicolumn{2}{c}{ Nonradial TE (Russell Measure) } \\
\hline & VRS & NIRS & VRS & NIRS \\
\hline Input-based & 0.8352 & 0.7951 & 0.6225 & 0.5892 \\
Output-based & 1.1250 & 1.1417 & 1.1250 & 1.1417
\end{tabular}

Note: The acronyms VRS and NIRS represent variable returns to scale and nonincreasing returns to scale, respectively.

Table 3. Summary of both radial and nonradial TE under VRS, CRS, and NIRS assumption.

\begin{tabular}{ccccc}
\hline Type of DEA & Base & RTS & Mean & SD \\
\hline & \multirow{3}{*}{ Input-based } & VRS & 0.8352 & 0.1843 \\
& & CRS & 0.7493 & 0.2075 \\
Radial TE (Farrell measure) & NIRS & 0.7951 & 0.2000 \\
& \multirow{2}{*}{ Output-based } & VRS & 1.1250 & 0.2020 \\
& & CRS & 1.4749 & 0.5490 \\
& & NIRS & 1.1417 & 0.1997 \\
& Input-based & VRS & 0.6225 & 0.2302 \\
& & CRS & 0.5295 & 0.2262 \\
Nonradial TE (Russell measure) & & 0.5892 & 0.2389 \\
& \multirow{2}{*}{ Output-based } & VRS & 1.1250 & 0.2020 \\
& & CRS & 1.4749 & 0.5490 \\
& & NIRS & 1.1417 & 0.1997 \\
\hline
\end{tabular}

Note: The acronyms VRS, CRS, and NIRS represent variable returns to scale, constant returns to scale, and nonincreasing returns to scale, respectively.

From Table 2, we can see that the input-based radial measure of technical efficiency is $83.5 \%$ under VRS and 79.5\% under NIRS. However, the nonradial measures of TE under VRS and NIRS are $62.2 \%$ and $59 \%$, respectively. Here, the average TE score of $83.5 \%$ indicated that the farmers could improve irrigation's overall performance by reducing around $14 \%$ of the irrigation input on average while achieving the same output level. Some of the farms are performing well, but many farms are performing well below the average TE (detailed analyses can be obtained from the corresponding author upon request). Radial measure of TE shows that around 35 percent of the total of 83 farmers have a TE score below average ranging from 33\% to $83.5 \%$, which indicates that more than one-third of the farms in this study are over-applying irrigation water. This inefficiency might be attributed to poor soil quality, land characteristics, and inefficient farm management. However, the nonradial measure of TE score indicates that around 45 percent of farms perform below average. To be more precise, around 33 percent of total farms under consideration are over-applying irrigation water by more than $50 \%$, which can be reduced by improving irrigation efficiency and other input management practices. These farms with lower TE scores have a great potential to reduce irrigation inefficiency by minimizing input without affecting the current output level adversely.

Similarly, output-based radial measures of TE under VRS and NIRS are 1.125 and 1.147, and nonradial TE under VRS and NIRS are 1.125 and 1.141, respectively. Here, the average value of the radial and nonradial TE score seems to be almost the same. It can be interpreted that the farms can improve their efficiency or reduce inefficiency proportionately by augmenting output. The average efficiency score of 1.125 implies that a farm can improve efficiency by augmenting outputs by $12.5 \%$. In the output-based model, farms with an efficiency score higher than one are inefficient and they can improve their performance by increasing output/yield without altering the input. To compare TE 
scores obtained using radial and nonradial measures assuming three different production technologies (CRS, VRS, and NIRS), we present summary statistics of efficiency scores in Table 3. The output-based radial and nonradial TE scores are the same, but the input-based efficiency scores under these two approaches differ widely (input-based TE scores under nonradial measure approach are lower than those of the radial measure approach, as the nonradial measure considers slacks and provides more precise TE scores).

Table 3 shows that the input-based TE scores under VRS and NIRS are similar, but significantly lower than in other cases. Additionally, we evaluate the scale efficiency of the data point using both input-based and output-based models. We estimate a smoothed heterogeneous bootstrap with 999 replications and estimate a Debreu-Farrell TE score, which is presented in Table 4.

Table 4. Bootstrapped Debreu-Farrell TE.

\begin{tabular}{ccccc}
\hline Base & RTS & Mean TE & SD & SE \\
\hline \multirow{3}{*}{ Output-based measure of TE } & VRS & 1.125 & 0.202 & - \\
& CRS & 1.475 & 0.549 & 1.300 \\
& NIRS & 1.142 & 0.200 & 1.017 \\
\hline \multirow{3}{*}{ Input-based measure of TE } & VRS & 0.835 & 0.184 & - \\
& CRS & 0.749 & 0.207 & 0.898 \\
& NIRS & 0.795 & 0.200 & 0.949 \\
\hline
\end{tabular}

The radial measure of TE scores with the bootstrap option is not different from previous estimates, as shown in Table 4. However, this option allows us to detect the scale of inefficient farms operating under different production technologies in both input-based and output-based measures. The scale efficiency status of each farm is presented in Table 5 (farm specific status concerning scale efficiency can be obtained from corresponding author upon request).

Table 5. Status of scale efficiency. DRS, decreasing returns to scale.

\begin{tabular}{ccccc}
\hline \multirow{2}{*}{$\begin{array}{c}\text { Input/Output Based } \\
\text { Indicator Variable }\end{array}$} & \multicolumn{3}{c}{ Indicator Variable if Statistically Efficient/Inefficient } \\
\cline { 2 - 5 } & Scale Efficient & Scale Inefficient & Scale Inefficient Due to IRS & Scale Inefficient Due to DRS \\
\hline Output-based number of vars. & 79 & 4 & 1 & 3 \\
Input-based number of vars. & 83 & 0 & - & - \\
\hline
\end{tabular}

The output-based model estimation using 999 bootstrap replications shows that four farms are scale inefficient, three farms (DMU: 1007, 1056, and 1073) exhibit scale inefficiency due to decreasing returns to scale, while one farm (DMU 1051) exhibits scale inefficiency due to increasing returns to scale. In the input-based model, all farms are scale-efficient.

The estimated TE scores obtained from input-based radial and nonradial measures are significantly different. Specifically, the TE score obtained from the input-based radial measure is around $20 \%$ higher than that obtained from the nonradial measure. The nonradial measure is considered more accurate than the radial measure because the radial measure ignores the possibility of slack that may occur in the constraints, but the nonradial approach accommodates such slacks in the estimation process. The average TE score of around 63\% obtained from the input-based Russell measure indicates that many producers are over-applying irrigation water by around 37\%. Our TE score is almost the same as that obtained by Watkins et al. $[23,24]$ in Arkansas rice production. In this situation, a significant amount of inefficiency minimization is desirable from both the financial and resource sustainability perspectives. For this, a policy that encourages producers to adopt efficient irrigation technology and promote pro-environmental behavior in society could be productive for water conservation. For example, Dolnicar et al. [34] note two critical factors in water conservation. Those are high levels of pro-environmental behavior and proactively seeking out information about water in Australia. Additionally, there could be some managerial issues that might be contributing to the inefficiency. More importantly, the furrow irrigation system, which is considered the least efficient, is dominant 
in Louisiana as indicated by the USDA. Our survey response supports this statement. In our survey, around 70 percent of total respondents have adopted a furrow irrigation system in soybean production without implementing irrigation management practices (surge flow, valve selection, computerized hole selection) [35]. Additionally, our survey results also show that around 50 percent of respondents have been utilizing a furrow irrigation system without implementing irrigation management practices in field crop production in Louisiana. In that situation, farmers should be encouraged to adopt surge valves, moisture sensors, flow meters, and computerized scheduling in their farm irrigation if possible to achieve a higher irrigation efficiency. Additionally, land leveling in an appropriate duration would help to minimize water use application. Watkins et al. [25] note that the zero graded topography of the farm could increase the irrigation efficiency by around $25 \%$. Technically, the model specification is correct based on the different test statistics. However, because of the limited information on sample size, temperature, rainfall, soil characteristics, and managerial information, the estimated results cannot be as good as they might be in a perfect information scenario. With the limited information, this is the best possible estimate we could obtain.

As in most empirical work, the main limitations of DEA measurement arise from the assumptions' failure. In any empirical work, endogeneity of explanatory variables, measurement error, or outliers is a common problem that needs to be adequately addressed for robust estimates. In this study, potential outliers were appropriately corrected. However, other possible issues are not considered, especially in the DEA method, as this method does not impose distributional restrictions. For a more accurate irrigation efficiency score, additional information, such as rainfall, temperature, soil characteristics, management information, and well characteristics, should be incorporated.

\section{Concluding Remarks}

This study estimated the technical efficiency of irrigation water use in Louisiana soybean production using both the input-based and output-based DEA approach. For this study, we conducted a farm-level survey to assess information regarding irrigation cost, the volume of water applied, and crop yield per acre. The commonly used DEA method ignores the possibility of slack that may occur in the constraints. To correct this issue, we used smoothed heterogeneous bootstrapping procedures in conventional DEA and supplemented it with a nonradial measure of efficiency measure. Bootstrap enabled us to obtain statistical inferences and test the hypothesis concerning technology dependency. The estimated results indicate that the average irrigation inefficiency among soybean farmers in Louisiana is about $37 \%$. This implies that, on average, Louisiana's soybean producers are over-applying irrigation water by about $37 \%$. Therefore, the producers have great potential to minimize this inefficiency by employing an appropriate management strategy. Additionally, we noted that three farms were exhibiting scale inefficiency due to decreasing returns to scale and one farm due to increasing returns to scale.

Indeed, irrigation efficiency information would allow producers to re-evaluate their irrigation scheduling to achieve higher water application efficiency. More specifically, soybean producers with lower irrigation efficiency scores are overapplying irrigation water, which might have contributed to increasing other input use applications, resulting in a lower profit margin. Rational farm producers tend to correct inefficient irrigation operation if they know their current status of irrigation efficiency score. Producers operating below average TE can optimize their irrigation efficiency through appropriate management practices (which may include irrigation re-scheduling, input management, and best irrigation management practices), which ultimately help minimize other input use applications.

There are some shortcomings associated with this study. The conclusions drawn from analyzing data from a single season are generally insufficient to formulate a valid long-run policy. However, conducting a farm-level survey for multiple years is expensive and time-consuming. Given that limitation, we assessed the irrigation efficiency score for the first time in Louisiana using mail survey data. The findings from this study can be a starting point for rigorous studies on the topic studied 
in the paper. In the future, multi-year data with more observations should be used for more robust analyses of the topic.

Author Contributions: Conceptualization, T.K.G. and K.P.P.; methodology, T.K.G. and K.P.P.; software, T.K.G.; validation, T.K.G., K.P.P. and K.M.G.; formal analysis, T.K.G. and K.P.P.; investigation, T.K.G. and K.P.P.; resources, P.K.P.P. and K.M.G.; data curation, T.K.G.; writing—original draft preparation, T.K.G. and K.P.P. writing-review and editing, T.K.G., K.P.P. and K.M.G.; visualization, T.K.G., K.P.P. and K.M.G.; supervision, K.P.P. and K.M.G.; project administration, K.P.P. and K.M.G.; funding acquisition, K.P.P. and K.M.G. All authors have read and agreed to the published version of the manuscript.

Funding: We gratefully acknowledge the financial support of the Louisiana Soybean and Grain Research and Promotion Board. Paudel's time on this paper was funded by the USDA Hatch Projects \#94382 and \#94483.

Acknowledgments: The authors are grateful to four anonymous reviewers for their constructive comments, which helped improve the paper's quality.

Conflicts of Interest: The authors declare no conflict of interest.

\section{References}

1. Ali, M.; Talukder, M. Increasing water productivity in crop production-A synthesis. Agric. Water Manag. 2008, 95, 1201-1213. [CrossRef]

2. Armstrong, D.P. Water use efficiency and profitability on an irrigated dairy farm in northern Victoria: A case study. Aust. J. Exp. Agric. 2004, 44, 137-144. [CrossRef]

3. Spencer, G.; Krutz, L.J.; Falconer, L.L.; Henry, W.B.; Henry, C.G.; Larson, E.J.; Pringle, H.C.; Bryant, C.J.; Atwill, R.L. Irrigation Water Management Technologies for Furrow-Irrigated Corn that Decrease Water Use and Improve Yield and On-Farm Profitability. CFTM 2019, 5, 180100. [CrossRef]

4. Amosson, S.; Almas, L.; Girase, J.R.; Kenny, N.; Guerrero, B.; Vimlesh, K.; Marek, T. Economics of Irrigation Systems. Texas A\&M Agrilife Extension, CollegeStation, TX, B-6113. 2011. Available online: https://aglifesciences. tamu.edu/baen/wp-content/uploads/sites/24/2017/01/B-6113-Economics-of-Irrigation-Systems.pdf (accessed on 10 February 2020).

5. Guerrero, B.; Amosson, S.; Almas, L.; Marek, T.; Porter, D. Economic Feasibility of Converting Center Pivot Irrigation to Subsurface Drip Irrigation. J. ASFMRA 2016, 77-88. Available online: https://www.asfmra.org/ resources/asfmra-journal/journal-archives (accessed on 9 February 2020).

6. Sargent, B.P. Water use in Louisiana, 2010. Louisiana Department of Transportation and Development, Special Report No. 17 (Revised December 2012). 2012. Available online: https://www.landcan.org/pdfs/ WaterUse2010.pdf. (accessed on 12 November 2020).

7. Peterson, J.M.; Ding, Y. Economic Adjustments to Groundwater Depletion in the High Plains: Do Water-Saving Irrigation Systems Save Water? Am. J. Agric. Econ. 2005, 87, 147-159. [CrossRef]

8. Paudel, K.P.; Limaye, A.S.; Hatch, L.U.; Cruise, J.F.; Musleh, F. Development of an optimal water allocation decision tool for the major crops during the water deficit period in the southeast united states. Nat. Resour. Model. 2008, 18, 281-306. [CrossRef]

9. Knox, J.W.; Kay, M.; Weatherhead, E. Water regulation, crop production, and agricultural water management-Understanding farmer perspectives on irrigation efficiency. Agric. Water Manag. 2012, 108, 3-8. [CrossRef]

10. Vico, G.; Porporato, A. From rainfed agriculture to stress-avoidance irrigation: II. Sustainability, crop yield, and profitability. Adv. Water Resour. 2011, 34, 272-281. [CrossRef]

11. Pereira, H.; Marques, R.C. An analytical review of irrigation efficiency measured using deterministic and stochastic models. Agric. Water Manag. 2017, 184, 28-35. [CrossRef]

12. Sayin, B.; Yilmaz, I.; Yılmaz, I. Comparing the Relative Efficiency of Irrigation Unions in Antalya, Turkey: A Data Envelopment Analysis. Water Econ. Policy 2015, 1, 1450005. [CrossRef]

13. Lansink, A.O.; Ondersteijn, C. Energy Productivity Growth in the Dutch Greenhouse Industry. Am. J. Agric. Econ. 2006, 88, 124-132. [CrossRef]

14. Dhungana, B.R.; Nuthall, P.L.; Nartea, G.V. Measuring the economic inefficiency of Nepalese rice farms using data envelopment analysis. Aust. J. Agric. Resour. Econ. 2004, 48, 347-369. [CrossRef]

15. Watto, M.A.; Mugera, A.W. Efficiency of irrigation water application in sugarcane cultivation in Pakistan. J. Sci. Food Agric. 2014, 95, 1860-1867. [CrossRef] [PubMed] 
16. Wang, G.; Lin, N.; Zhou, X.; Li, Z.; Deng, X. Three-Stage Data Envelopment Analysis of Agricultural Water Use Efficiency: A Case Study of the Heihe River Basin. Sustain. 2018, 10, 568. [CrossRef]

17. Ren, C.; Li, R.H.; Guo, P. Two-Stage DEA Analysis of Water Resource Use Efficiency. Sustainability 2016, 9, 52. [CrossRef]

18. Gadanakis, Y.; Bennett, R.; Park, J.; Areal, F.J. Improving productivity and water use efficiency: A case study of farms in England. Agric. Water Manag. 2015, 160, 22-32. [CrossRef]

19. Ntantos, P.N.; Karpouzos, D.K. Application of data envelopment analysis and performance indicators to irrigation systems in Thessaloniki Plain (Greece). Int. J. Eng.Nat. Sci. 2010, 4, 133-139.

20. Ali, K.; Klein, K.K. Water Use Efficiency and Productivity of the Irrigation Districts in Southern Alberta. Water Resour. Manag. 2014, 28, 2751-2766. [CrossRef]

21. Liu, J.; Zhang, J.; Fu, Z. Tourism eco-efficiency of Chinese coastal cities - Analysis based on the DEA-Tobit model. Ocean Coast. Manag. 2017, 148, 164-170. [CrossRef]

22. Goyal, J.; Kaur, H.; Aggarwal, A. Investigating the Technical and Scale Efficiencies of Indian Textile Industry: A Target Setting Based Analysis through DEA. IUP J. Oper. Manag. 2017, 16, 16-38.

23. Watkins, K.B.; Hristovska, T.; Mazzanti, R.; Wilson, C.E.; Schmidt, L. Measurement of Technical, Allocative, Economic, and Scale Efficiency of Rice Production in Arkansas Using Data Envelopment Analysis. J. Agric. Appl. Econ. 2014, 46, 89-106. [CrossRef]

24. Watkins, K.B.; Henry, C.G.; Hardke, J.T.; Mane, R.U.; Mazzanti, R.; Baker, R. Efficiency Measurement of Irrigation Water and Other Inputs in Arkansas Rice Production Using Data from the Rice Research Verification Program. In BR Wells Arkansas Rice Research Studies; Norman, R.J., Moldenhauer, K.A.K., Eds.; University of Arkansas System Division of Agriculture: Fayetteville, AR, USA, 2019; Volume 659, pp. 424-430.

25. Watkins, K.B.; Henry, C.G.; Hardke, J.T.; Mane, R.U.; Mazzanti, R.; Baker, R. Effects of Field Characteristics on Irrigation Water Efficiency in Arkansas Rice Production. In BR Wells Arkansas Rice Research Studies; Norman, R.J., Moldenhauer, K.A.K., Eds.; University of Arkansas System Division of Agriculture: Fayetteville, AR, USA, 2018; Volume 659, pp. 431-438.

26. Charnes, A.; Cooper, W.W.; Rhodes, E. Measuring the efficiency of decision making units. Eur. J. Oper. Res. 1978, 2, 429-444. [CrossRef]

27. Banker, R.D.; Charnes, A.; Cooper, W.W. Some Models for Estimating Technical and Scale Inefficiencies in Data Envelopment Analysis. Manag. Sci. 1984, 30, 1078-1092. [CrossRef]

28. Lee, C. An Efficient Data Envelopment Analysis with Large Data Set in Stata. Stata J. 2010, 10, $267-280$.

29. Farrell, M.J. The measurement of productive efficiency. J. R. Stat. Soc. Series A 1957, 120, 253-281. [CrossRef]

30. Cooper, W.W.; Seiford, L.M.; Tone, K. Introduction to Data Envelopment Analysis and Its Uses: With DEA-Solver Software and References; Springer Science \& Business Media: New York, NY, USA, 2006.

31. Coelli, T.; Rao, D.S.P.; Battese, G.E. An Introduction to Efficiency and Productivity Analysis; Springer Science and Business Media LLC: New York, NY, USA, 1998.

32. Färe, R.; Lovell, C.K. Measuring the technical efficiency of production. J. Econ. Theory 1978, 19, $150-162$. [CrossRef]

33. Badunenko, O.; Mozharovskyi, P. Nonparametric Frontier Analysis Using Stata. Stata J. Promot. Commun. Stat. Stata 2016, 16, 550-589. [CrossRef]

34. Dolnicar, S.; Hurlimann, A.; Grün, B. Water conservation behavior in Australia. J. Environ. Manag. 2012, 105, 44-52. [CrossRef]

35. Gautam, T.K. Three Essays on Irrigation Water Management in Louisiana Crop Production. LSU Dr. Diss. 2019. Available online: https://digitalcommons.lsu.edu/gradschool_dissertations/4893 (accessed on 10 February 2020).

Publisher's Note: MDPI stays neutral with regard to jurisdictional claims in published maps and institutional affiliations.

(C) 2020 by the authors. Licensee MDPI, Basel, Switzerland. This article is an open access article distributed under the terms and conditions of the Creative Commons Attribution (CC BY) license (http://creativecommons.org/licenses/by/4.0/). 